ACCEPTED MANUSCRIPT

\title{
Comparison of optoelectrical characteristics between Schottky and Ohmic contacts to $-\mathrm{Ga}<\mathrm{sub}>2</$ sub $>\mathrm{O}<$ sub $>3</$ sub $>$ thin film
}

To cite this article before publication: Zeng Liu et al 2019 J. Phys. D: Appl. Phys. in press https://doi.org/10.1088/1361-6463/ab596f

\author{
Manuscript version: Accepted Manuscript \\ Accepted Manuscript is "the version of the article accepted for publication including all changes made as a result of the peer review process, \\ and which may also include the addition to the article by IOP Publishing of a header, an article ID, a cover sheet and/or an 'Accepted \\ Manuscript' watermark, but excluding any other editing, typesetting or other changes made by IOP Publishing and/or its licensors" \\ This Accepted Manuscript is @ 2019 IOP Publishing Ltd.
}

During the embargo period (the 12 month period from the publication of the Version of Record of this article), the Accepted Manuscript is fully protected by copyright and cannot be reused or reposted elsewhere.

As the Version of Record of this article is going to be / has been published on a subscription basis, this Accepted Manuscript is available for reuse under a CC BY-NC-ND 3.0 licence after the 12 month embargo period.

After the embargo period, everyone is permitted to use copy and redistribute this article for non-commercial purposes only, provided that they adhere to all the terms of the licence https://creativecommons.org/licences/by-nc-nd/3.0

Although reasonable endeavours have been taken to obtain all necessary permissions from third parties to include their copyrighted content within this article, their full citation and copyright line may not be present in this Accepted Manuscript version. Before using any content from this article, please refer to the Version of Record on IOPscience once published for full citation and copyright details, as permissions will likely be required. All third party content is fully copyright protected, unless specifically stated otherwise in the figure caption in the Version of Record.

View the article online for updates and enhancements. 


\title{
Comparison of optoelectrical characteristics between Schottky and
}

\section{Ohmic contacts to $\beta-\mathrm{Ga}_{2} \mathrm{O}_{3}$ thin film}

\section{Zeng Liu ${ }^{1}$, Yusong Zhi ${ }^{1}$, Shan $\mathrm{Li}^{1}$, Yuanyuan $\mathrm{Liu}^{2,5}$, Xiao Tang ${ }^{3}$, Zuyong Yan ${ }^{1}$, Peigang $\mathrm{Li}^{1}$, Xiaohang $\mathrm{Li}^{3}$, Daoyou $\mathrm{Guo}^{4}$, Zhenping $\mathrm{Wu}^{1}$ and Weihua Tang ${ }^{1}$}

${ }^{1}$ Laboratory of Information Functional Materials and Devices, School of Science \& State Key Laboratory of Information Photonics and Optical Communications, Beijing University of Posts and Telecommunications, Beijing 100876, People's Republic of China

${ }^{2}$ Center of Materials Science and Optoelectronics Engineering, University of Chinese Academy of Sciences, Beijing 100049, People's Republic of China

${ }^{3}$ Advanced Semiconductor Laboratory, King Abdullah University of Science and Technology (KAUST), Thuwal 23955-6900, Saudi Arabia

${ }^{4}$ Center for Optoelectronics Materials and Devices, Department of Physics, Zhejiang Sci-Tech University, Hangzhou 310018, People's Republic of China

${ }^{5}$ The Engineering Research Center for Semiconductor Integrated Technology, Institute of Semiconductors, Chinese Academy of Sciences, Beijing 100083, People's Republic of China

E-mail: zengliu@bupt.edu.cn,pgli@bupt.edu.cn and whtang@bupt.edu.cn

\begin{abstract}
Schottky and Ohmic contacts are key matters affecting carrier transport in oxide semiconductor based electrical and optical devices. For $\mathrm{Ga}_{2} \mathrm{O}_{3}$, the comparison of optoelectrical behaviors and the fundamental physical mechanism between these two contacts are not well known yet. In this work, $\beta-\mathrm{Ga}_{2} \mathrm{O}_{3}$ thin films were grown via metal-organic chemical vapor deposition then deposited with symmetrical Ni/Au (Schottky) or Ti/Au (Ohmic) contacts. Optoelectrical measurements show that the Ohmic contacted device exhibits superior responsivities thanks to their higher photocurrents. While for the Schottky contacted device, firstly, it has faster response speed, secondly it exhibits larger photo-to-dark current ratios owing to their low dark current. Specifically, the voltage- and light intensity-dependent responsivity and detectivities of the Schottky and Ohmic contacted devices were measured and discussed under the consideration of different voltages and UV light intensities.
\end{abstract}

Keywords: $\beta-\mathrm{Ga}_{2} \mathrm{O}_{3}$, Schottky and Ohmic contacts, optoelectrical characteristics, metal-organic chemical vapor deposition (MOCVD)

\section{Introduction}

Due to the promising applications in information communications, chemical/biological analysis, flame detection, and environmental protection, ultraviolet (UV) photodetectors have drawn extensive research interests in the past years. Among them, the UV solar-blind detectors operating 
in a wavelength range from $200 \mathrm{~nm}$ to $280 \mathrm{~nm}$ are the solid choice for ozone sensing with low false alarming rate [1-3]. The performances of photodetectors, to a large degree, depend on the nature and modified properties of the selected materials [4]. Specifically, as one of the typical wide bandgap semiconductors, $\beta-\mathrm{Ga}_{2} \mathrm{O}_{3}$ not only has a ultra-wide bandgap of 4.5-4.9 eV (responding in the UV solid-blind regime), but also high thermal and chemical stability, high critical breakdown field of 6-8 MV/cm (allowing high voltage and strong radiation operations) [5, 6], therefore allowing them extensively employed to fabricate UV solar-blind photodetectors [7] in the forms of thin films [8-12], bulk single crystals [13-16] nanostructures [17-20] and heterogeneous structures $[20-26]$.

Metal-Semiconductor-Metal (MSM) structure is a typically and widely used electrode pattern in photodetectors [27], in which either Ohmic or Schottky metal-semiconductor (M-S) contacts are employed in line with the requirements of the applications. The Ohmic contacted detectors (regarding as radiation-sensitive resistors), referenced as photoconductive, are presented by the change of resistance of the materials due to the external light stimulation, showing the intrinsic feature of materials $[1,8,28,29]$. While the Schottky contacted detectors could show some modified performances owing to the efficient control of carrier transport via tuning the M-S interface barrier and the thickness of the depletion layer at the M-S interface [29-31]. For instance, Guo et al grew $\beta-\mathrm{Ga}_{2} \mathrm{O}_{3}$ thin film by laser molecular beam epitaxy and displayed a good Ohmic electrical behavior with dark current of $45 \mathrm{nA}$ and rise time of $1.91 \mathrm{~s}$, while the Schottky M-S behavior was illustrated after annealing, and the dark current and rise time were changed to be $0.3 \mathrm{nA}$ and $0.62 \mathrm{~s}$, respectively [8]. Other than the semiconductor and/or device processing, the contacting types depend on the choice of contacted metals [32], i.e., the difference between the work function of metal and the electron affinity of $\mathrm{Ga}_{2} \mathrm{O}_{3}$. An et al achieved good Ohmic contact in their photodetector, this device shown decent photoresponsivity and wavelength selectivity, while a long response time of $19 \mathrm{~s}$ [33]. As opposed to this, Chen et al demonstrated a fast responding $\mathrm{Au} / \beta-\mathrm{Ga}_{2} \mathrm{O}_{3}$ nanowires array photodetector with faster decay time of $64 \mu$ s [34]. Such a UV detector may be contributed to the development of a depletion layer at the $\mathrm{Au} / \beta-\mathrm{Ga}_{2} \mathrm{O}_{3}$ interface, which could restrain the separation of electron-hole pairs and conduce to the practicability more easily. In all, the M-S contact is a vital matter to determine the carrier transport and then affect the detector performances [35-39], due to 
the differences between work function of metals and electron affinity of $\mathrm{Ga}_{2} \mathrm{O}_{3}$. However, to the best of our current knowledge, a systematic comparison of Schottky and Ohmic contacts to $\mathrm{Ga}_{2} \mathrm{O}_{3}$ and the influences on photodetector performances are less reported.

In this work, $\beta-\mathrm{Ga}_{2} \mathrm{O}_{3}$ thin films were grown via metal-organic chemical vapor deposition (MOCVD) then deposited with $\mathrm{Ni} / \mathrm{Au}$ (Schottky) or Ti/Au (Ohmic) contacts. The optoelectrical behaviors, photogenerated currents, time-dependent photoresponse, photoreponsivities, detectivities, response time were systematically measured on the as-prepared devices. These aforementioned performances of the $\mathrm{Ni} / \mathrm{Au}$ (Schottky) and $\mathrm{Ti} / \mathrm{Au}(\mathrm{Ohmic})$ contacted devices were systematically compared and discussed. In addition, the inherent physical mechanism of this practical phenomenon was elucidated for its further optoelectronic applications.

\section{Experimental}

The deposition of $\beta-\mathrm{Ga}_{2} \mathrm{O}_{3}$ thin film on c-plane sapphire substrate was performed via a customized MOCVD thin film growth system with a close-coupled showerhead reactor. Triethylgallium (TEGa) and high-purity ( $5 \mathrm{~N}$ ) oxygen gas were used as gallium and oxygen sources, respectively. TEGa was stored in a stainless steel bubbler, which was kept at temperature of $35^{\circ} \mathrm{C}$ and pressure of 760 Torr. Oxygen gas was delivered into the growth chamber, and a gas ratio of 6000 SCCM was set. On the basis of the set oxygen flow, the $[\mathrm{O} / \mathrm{Ga}]$ molar ratio was regulated to be $\sim 1657$. Specifically, according to the Antoine's equation $\log \left(P_{M O}\right)=\mathrm{a}-\mathrm{b} / \mathrm{T}$ [41, 42], where $\mathrm{P}_{\mathrm{MO}}$ is the vapor pressure of TMGa, a and $\mathrm{b}$ are the Antoine constants, and $\mathrm{T}$ is the thermodynamic temperature of TMGa. $n_{m o}=\frac{F \times P_{M o}}{V_{m} \times\left(P_{b u b}-P_{M O}\right)}$, where $\mathrm{n}_{\mathrm{mo}}$ is the molar flow rate of TMGa, $\mathrm{F}$ is the flow rate of carrier gas, $\mathrm{V}_{\mathrm{m}}=22414 \mathrm{~cm}^{3} / \mathrm{mol}$ (ideal gas molar volume), $\mathrm{P}_{\text {bub }}$ is the pressure inside the bubbler. $n_{O 2}=$ $\frac{F_{O}}{V_{m}}$, where $\mathrm{n}_{\mathrm{O} 2}$ is the molar flow rate of $\mathrm{O}_{2}, \mathrm{~F}_{\mathrm{O}}$ is the flow rate of $\mathrm{O}_{2}$. Therefore, the $[\mathrm{O} / \mathrm{Ga}]$ molar ratios in the experiment could be expressed as: $[\mathrm{O} / \mathrm{Ga}]=\frac{n_{02}}{n_{m o}}=\frac{5.35 \times 10^{-1}}{3.23 \times 10^{-4}} \sim 1657$. The growth process was maintained for 15 min under a fixed growth chamber condition with temperature of $735^{\circ} \mathrm{C}$ and pressure of 25 Torr.

The symmetrical Ni/Au and/or Ti/Au metal electrodes were patterned on the surface of $\beta$ $\mathrm{Ga}_{2} \mathrm{O}_{3}$ thin film by means of electron beam evaporation, conventional photolithography and lift-off techniques. The same photomask was employed to pattern the Ni/Au $(120 \mathrm{~nm} / 180 \mathrm{~nm})$ and Ti/Au 
$(120 \mathrm{~nm} / 180 \mathrm{~nm})$ metal electrodes. The quadrate electrodes are $400 \mu \mathrm{m}$ wide and $400 \mu \mathrm{m}$ long, and $200 \mu \mathrm{m}$ spacing gap. Calculated from the scale of electrode patterns, the efficient irradiant area could be about $8 \times 10^{4} \mu \mathrm{m}^{2}$ for both two electrode types. In details, after patterning the $\mathrm{Ti} / \mathrm{Au}$ electrodes, the fabricated devices were annealed in $\mathrm{N}_{2}$ at $200^{\circ} \mathrm{C}$ for $60 \mathrm{~s}$, in order to achieve better Ohmic contacts [42]. Before the Ni/Au electrodes deposition, the $\beta-\mathrm{Ga}_{2} \mathrm{O}_{3}$ thin film was surface treated by $\mathrm{O}_{2}$ plasmas for $30 \mathrm{~s}$ [43-45]. This is because the Schottky contacts on oxide semiconductors are often challenged by the distinct surface charge accumulation layer [42, 44-47]. The metal-semiconductor contact region is the key issue for successful fabrication of Schottky contacts on various oxide semiconductors, including $\beta-\mathrm{Ga}_{2} \mathrm{O}_{3}$ studied in this work. The $\mathrm{O}_{2}$ plasmas treatments allow us to increase the oxygen content at the $\mathrm{Ni} / \mathrm{\beta}_{-}-\mathrm{Ga}_{2} \mathrm{O}_{3}$ interface, inducing interface charge reduction for Ni contacts on the surface of $\beta-\mathrm{Ga}_{2} \mathrm{O}_{3}$ and the improvement of Schottky characteristics $[43,46,49,50]$. The current-voltage (I-V) characteristics are performed with a Keithley 4200 semiconductor parameter analyzer. The measurement of time-dependent photoresponse is finished by using an UV lamp with various intensities through tuning the distance between measuring sample and the UV light source, and the UV light intensities could be read by a light receptor and a display instrument. The crystal structure of the $\beta-\mathrm{Ga}_{2} \mathrm{O}_{3}$ thin film was analyzed by a Bruker D8 Advance x-ray diffractometer (XRD) with $\mathrm{Cu} \mathrm{K}_{\alpha}(\lambda \sim 1.5405 \AA)$ radiation. All the measurements in this work were executed in air at room temperature.

\section{Results and discussion}

As shown in figure 1(a), the X-ray diffraction (XRD) pattern of the $\beta-\mathrm{Ga}_{2} \mathrm{O}_{3}$ thin film grown by MOCVD on c-plane sapphire substrate indicates a good single crystallinity with highly ordered peaks along $(\overline{2} 01),(\overline{4} 02)$ and $(\overline{6} 03)$ directions (JCPDS \#43-1012), except for the sharp (0006) peak from the sapphire substrate (JCPDS \#46-1212). Figure 1(b) shows a schematic diagram of the fabricated $\beta-\mathrm{Ga}_{2} \mathrm{O}_{3}$ thin film based MSM structured UV solar-blind photodetector. The side length of the quadrate electrode pattern is $400 \mu \mathrm{m}$, and the spacing distance between two symmetrical electrodes is $200 \mu \mathrm{m}$. So, the efficient UV light radiant area (S) could be calculated to be $8 \times 10^{4}$ $\mu \mathrm{m}^{2}$. As key influences on devices output performances, the morphological information of the used $\beta-\mathrm{Ga}_{2} \mathrm{O}_{3}$ thin film is provided. The scanning electron microscope (SEM) image is displayed in figure 
1(c), the uniformly claviform grains with well-defined boundaries prove good crystallization of the prepared $\beta-\mathrm{Ga}_{2} \mathrm{O}_{3}$ thin film. The plane and tridimensional atomic force microscope (AFM) images are shown in figure 2(d) and (e), respectively, the root mean square (RMS) roughness is $1.234 \mathrm{~nm}$.

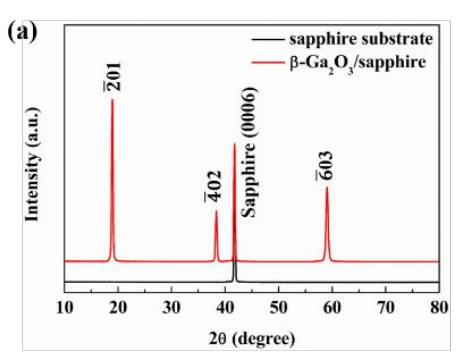

(d)

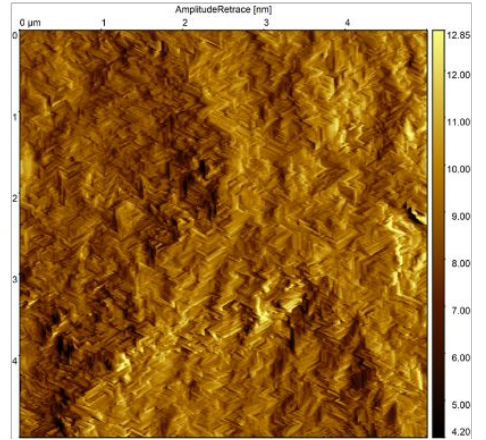

(b)

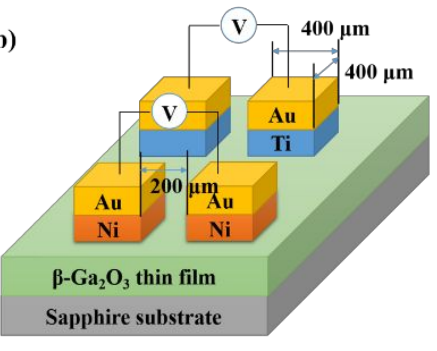

(c)

(e)

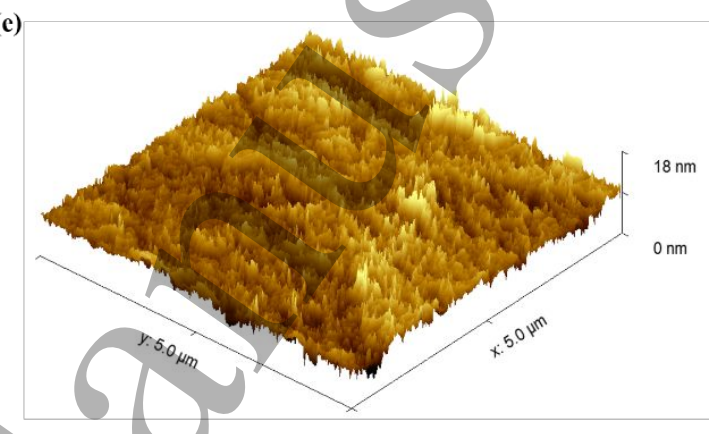

Figure 1. (a) The XRD pattern of the MOCVD-grown $\beta-\mathrm{Ga}_{2} \mathrm{O}_{3}$ thin film, (b) the schematic diagram of the fabricated $\beta-\mathrm{Ga}_{2} \mathrm{O}_{3}$ thin film based metal-semiconductor-metal (MSM) structured UV solarblind photodetector. (c) The SEM image of the surface of the $\beta-\mathrm{Ga}_{2} \mathrm{O}_{3}$ thin film. (d) Plane AFM surface morphology image of the $\beta-\mathrm{Ga}_{2} \mathrm{O}_{3}$ thin films with $5 \times 5 \mu \mathrm{m}^{2}$ scanning area, and the tridimensional AFM image is displayed in (e).

Figure 2(a) shows the dark I-V characteristics of the typical back-to-back MSM structured Schottky and Ohmic $\beta-\mathrm{Ga}_{2} \mathrm{O}_{3}$ thin film based UV solar-blind photodetectors, in the voltage range from $-5 \mathrm{~V}$ to $5 \mathrm{~V}$. The good symmetrical I-V curves suggest a good quality and uniform $\beta-\mathrm{Ga}_{2} \mathrm{O}_{3}$ thin film, and consistent electrode patterns. At applied voltage of $5 \mathrm{~V}$, the dark current $\left(\mathrm{I}_{\text {dark }}\right)$ of the Schottky and Ohmic devices are $2.65 \times 10^{-13} \mathrm{~A}$ and $9.77 \times 10^{-13} \mathrm{~A}$, respectively. The $\mathrm{I}_{\text {dark }}$ obtained from Schottky devices is more than four times lower than that from Ohmic devices, due to the efficient constraint of carriers (electrons) transport by the interface barrier of $\mathrm{Ni} / \beta-\mathrm{Ga}_{2} \mathrm{O}_{3}$, instead of the light sensitive I-V behaviors like a resistor [1, 29]. Seen from figure 2(b), the photocurrent ( $\mathrm{I}_{\text {photo }}$ ) at $5 \mathrm{~V}$ is $5.58 \times 10^{-8} \mathrm{~A}$ and $9.76 \times 10^{-8} \mathrm{~A}$ for Schottky and Ohmic devices, respectively, and accordingly the photo-to-dark current ratio $\left[\left(\mathrm{I}_{\text {photo }}-\mathrm{I}_{d a r k}\right) / \mathrm{I}_{\text {dark }}\right]$ at $5 \mathrm{~V}$ is $\sim 2.1 \times 10^{5}$ and $\sim 1.0 \times 10^{5}$. The photoresponse, $\left(\mathrm{I}_{\text {photo }}-\mathrm{I}_{\text {dark }}\right) / \mathrm{I}_{\text {dark }}$, in Schottky device is superior to that in Ohmic devices, which 
is consistent with the description in reference 8 . Meanwhile, the I-V curves of both the Ohmic and Schottky contacted photodetectors are shown in figure 2(c) and (d), respectively. Larger UV light intensities contribute to larger $\mathrm{I}_{\text {photo }}$ for both two typed devices. The "shoulders" in semi-log scale I-V curves of Schottky devices in figure 2(b) maybe due to the non-uniformity Schottky barriers [51]. As indicated in figure 2(c), the $\mathrm{I}_{\text {photo }}$ of the Ohmic device exhibits a good linear characteristic, suggesting a great stability of $\mathrm{UV}$ light response. The incident photons are absorbed in $\beta-\mathrm{Ga}_{2} \mathrm{O}_{3}$ thin

(a)

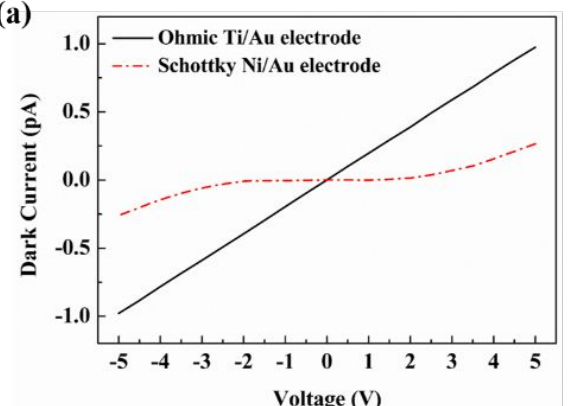

(c)

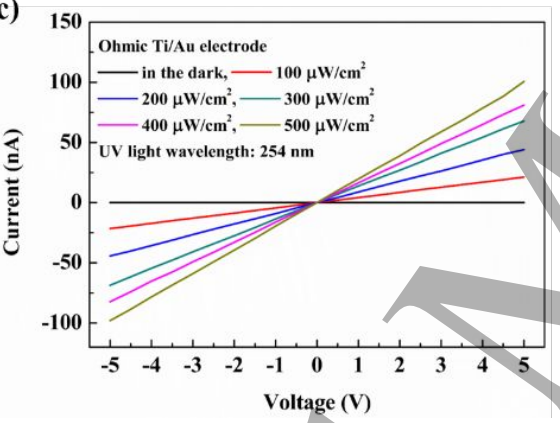

(b)

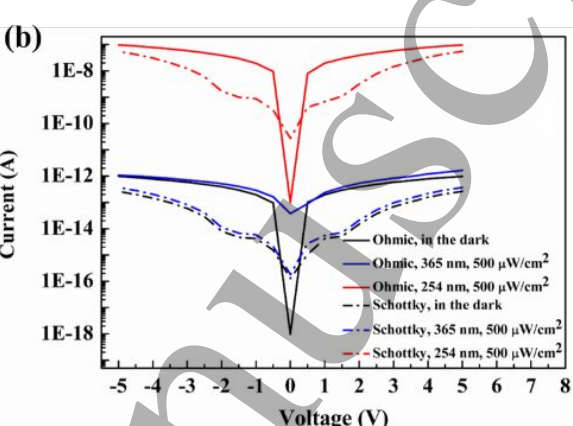

(d)

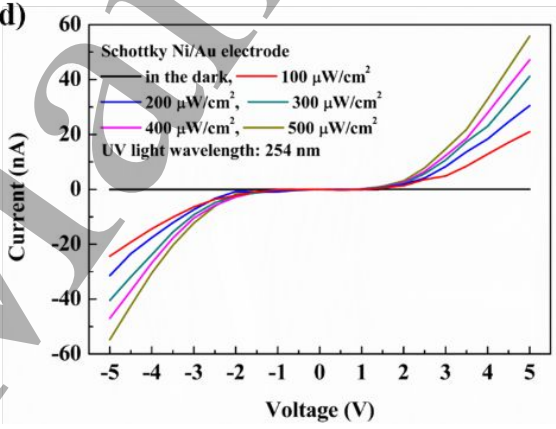

Figure 2. (a) The linear-scale $\mathrm{I}-\mathrm{V}$ characteristics of the MOCVD-grown $\beta-\mathrm{Ga}_{2} \mathrm{O}_{3}$ thin film based photodetector in the dark for Schottky Ni/Au (red dot line) and Ohmic Ti/Au contacts (black full line). (b) The semi log-scale I-V characteristics of both the Schottky $\left(\mathrm{Ni} / \mathrm{\beta}-\mathrm{Ga}_{2} \mathrm{O}_{3} / \mathrm{Ni}\right)$ and Ohmic (Ti/ $/ \mathrm{Ga}_{2} \mathrm{O}_{3} / \mathrm{Ti}$ ) devices in the dark, under the $254 \mathrm{~nm}$ and $365 \mathrm{~nm}$ UV light illuminations with intensities of $500 \mu \mathrm{W} / \mathrm{cm}^{2}$. The linear-scale I-V curves of (c) Ohmic devices and (d) Schottky devices in the dark and under the $254 \mathrm{~nm}$ UV light illuminations with intensities from $100 \mu \mathrm{W} / \mathrm{cm}^{2}$ to $500 \mu \mathrm{W} / \mathrm{cm}^{2}$, step is $100 \mu \mathrm{W} / \mathrm{cm}^{2}$.

film and changed the electronic energy distribution, leading to a disciplinary and linear increase of $\mathrm{I}_{\text {photo }}$ [1]. The high $\left(\mathrm{I}_{\text {photo }}-\mathrm{I}_{\text {dark }}\right) / \mathrm{I}_{\text {dark }}$ of $\sim 10^{5}$ and the excellent linearity of $\mathrm{I}_{\text {photo }}$ verify that the photodetectors presented in this work are sensitive and stable. In addition to the results in figure 2(b), the photocurrent under the $365 \mathrm{~nm}$ UV light illumination show a small increase, compared to that in the dark, the small increase maybe due to the defects in $\beta-\mathrm{Ga}_{2} \mathrm{O}_{3}$ thin film and/or the unpurified UV light source [14]. This little variation between $365 \mathrm{~nm}$ light illumination and dark 
condition suggests an outstanding wavelength selectivity, in comparison to the sharp increasing $\mathrm{I}_{\text {photo }}$ under $254 \mathrm{~nm}$ UV light illumination.

Figure 3 shows the time-dependent photoresponse and the voltage-dependent $\mathrm{I}_{\text {photo }}$ of the $\beta$ $\mathrm{Ga}_{2} \mathrm{O}_{3}$ thin film grown by MOCVD at voltages from $1 \mathrm{~V}$ to $5 \mathrm{~V}$ under the $254 \mathrm{~nm} \mathrm{UV}$ light illumination with a light intensity of $500 \mu \mathrm{W} / \mathrm{cm}^{2}$. The $\mathrm{I}_{\text {photo }}$ increase with the applied voltage increase for both Schottky and Ohmic contacted photodetectors, which can be clearly seen in figure 3(a) and (b). As indicated by figure 3(c), the $\mathrm{I}_{\text {photo }}$ in Ohmic devices are higher than that in Schottky devices. Taking the time-dependent $\mathrm{I}_{\text {photo }}\left(5 \mathrm{~V}\right.$ and $\left.500 \mu \mathrm{W} / \mathrm{cm}^{2}\right)$ as an example, the rise and decay time $\left(\tau_{\mathrm{r}}\right.$ and $\left.\tau_{\mathrm{d}}\right)$ of the devices are exhibited and discussed, as displayed in figure 4 . In figure 4(a) and (b), the fitting of the time-dependent photo responding curves are according to an exponential relaxation equation [52]:

$$
\mathrm{I}=\mathrm{I}_{0}+\mathrm{A} e^{-t / \tau}
$$

where $\mathrm{I}_{0}$ is the stable state photocurrent, $\mathrm{A}$ is a constant, $t$ is the time, $\tau$ is a relaxation time constant. $\tau_{\mathrm{r}}$ and $\tau_{\mathrm{d}}$ are the rise and decay edge of the time constants, respectively. In addition, the $\mathrm{I}_{\text {photo }}$ at different voltages ranging from $1 \mathrm{~V}$ to $5 \mathrm{~V}$ are shown in figure $4(\mathrm{c})$. The $\tau_{\mathrm{r}}$ and $\tau_{\mathrm{d}}$ of Ohmic devices are larger than that of Schottky devices, suggesting a faster photoresponse of Schottky devices compared to that of the Ohmic devices. The faster photoresponse in Schottky devices verifies a rapid change of electron concentration as soon as the UV light is radiated on the surface of the $\beta$ $\mathrm{Ga}_{2} \mathrm{O}_{3}$ thin film, while the slower photoresponse of Ohmic devices maybe due to the electron traps at M-S interface, caused by some defects at the M-S interface and/or in the $\beta-\mathrm{Ga}_{2} \mathrm{O}_{3}$ thin film. What could be clearly seen in figure 4(a) and (b) is that the rise edge and decay edge for Schottky and Ohmic devices are different obviously. Using equation (1), the $\tau_{\mathrm{r}}$ and $\tau_{\mathrm{d}}$ of Ohmic devices are 0.706 $\mathrm{s}$ and $0.29 \mathrm{~s}$, respectively, which are larger than those of $0.31 \mathrm{~s}$ and $0.156 \mathrm{~s}$ of Schottky devices. In detail, the voltage-dependent $\mathrm{I}_{\text {photo }}$ are given in figure $4(\mathrm{c})$ and $(\mathrm{d})$, the $\tau_{\mathrm{r}}$ and $\tau_{\mathrm{d}}$ presented here indicate that the Schottky device has faster photoresponse than the Ohmic devices at the applied voltages range from $1 \mathrm{~V}$ to $5 \mathrm{~V}$. Moreover, for these two typed devices, the larger applied voltages could achieve faster photoresponse, i.e., smaller $\tau_{\mathrm{r}}$ and $\tau_{\mathrm{d}}$, owing to the larger kinetic energy that electron acquired from higher voltages [12]. In general, the fast light response could be attributed to the rapid change of the electron concentration of the $\beta-\mathrm{Ga}_{2} \mathrm{O}_{3}$ thin film as soon as the UV light 
was turned on and/or off. For Ohmic ( $\mathrm{Ti} / \mathrm{Au})$ devices, the response process was deeply affected by the interface trapping and oxygen vacancies defects, therefore, the rise and decay time of the Ohmic devices are long. However, for the Schottky $(\mathrm{Ni} / \mathrm{Au})$ devices after $\mathrm{O}_{2}$ plasmas treatments at the $\mathrm{Ni} / \mathrm{\beta}-$ $\mathrm{Ga}_{2} \mathrm{O}_{3}$ interface, decent Schottky electrical behaviors were obtained, and also, the electrons can be photogenerated and recombined faster than that of the Ohmic devices, due to the weaker influences of traps and defects on the light responses [8, 53-55].


Figure 3. The continuous time-dependent photoresponse of the $\beta-\mathrm{Ga}_{2} \mathrm{O}_{3}$ thin film grown by MOCVD at voltages from $1 \mathrm{~V}$ to $5 \mathrm{~V}$ under the $254 \mathrm{~nm}$ UV light illumination with a light intensity of $500 \mu \mathrm{W} / \mathrm{cm}^{2}$ for (a) Ohmic devices and (b) Schottky devices. (c) The voltage-dependent photocurrents under the $254 \mathrm{~nm}$ UV light illumination with a light intensity of $500 \mu \mathrm{W} / \mathrm{cm}^{2}$.
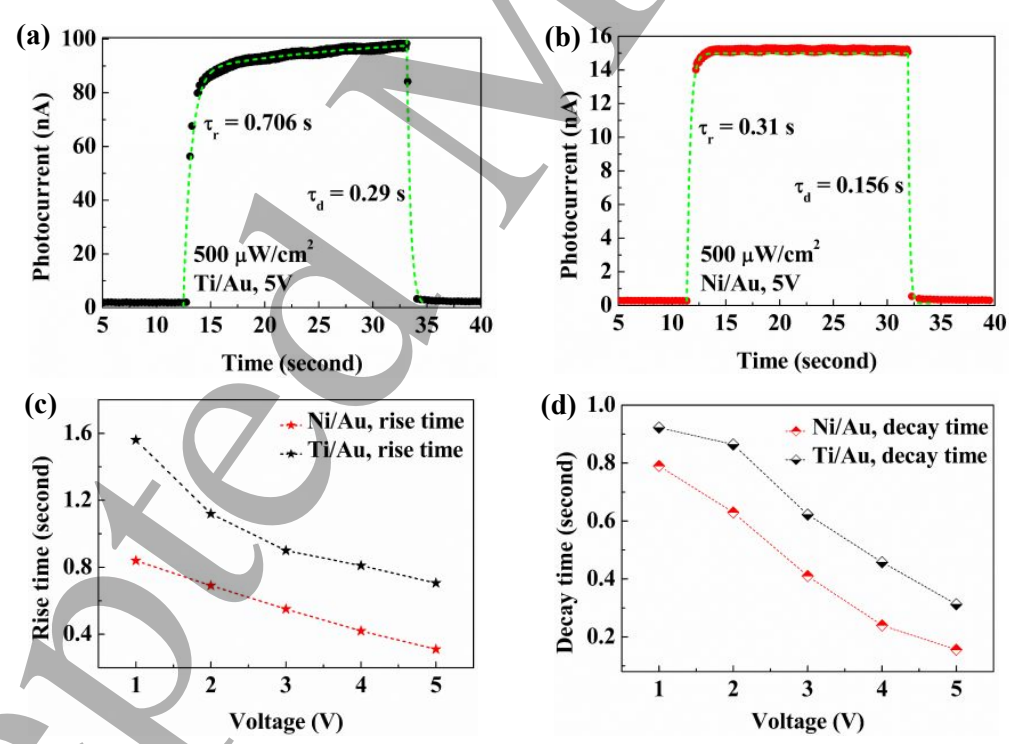

Figure 4. The rise and decay time of the $\beta-\mathrm{Ga}_{2} \mathrm{O}_{3}$ thin film based photodetector of (a) Ohmic devices and (b) Schottky devices responding to the $254 \mathrm{~nm}$ UV light with a light intensity of $500 \mu \mathrm{W} / \mathrm{cm}^{2}$ at $5 \mathrm{~V}$, with $\mathrm{Ti} / \mathrm{Au}$ and $\mathrm{Ni} / \mathrm{Au}$ electrodes, respectively. The voltage-dependent (c) rise time and (d) decay time for Schottky and Ohmic devices.

As reported, the band structure of $\beta-\mathrm{Ga}_{2} \mathrm{O}_{3}$ along a continuous path in the Brillouin zone has been studied [56-59]. According to these results, the conduction-band minimum $\beta-\mathrm{Ga}_{2} \mathrm{O}_{3}$ material 
is located at $\Gamma$ point, and the corresponding bandgap is only about $0.04 \mathrm{eV}$ larger than those at other points in the band structure [57]. In addition, the secondary conduction bands at $\mathrm{Z}$ and $\mathrm{Y}$ points just have minimal values, as well as the minima at $\mathrm{N}$ and $\mathrm{X}$ points. So the bandgap of $\beta-\mathrm{Ga}_{2} \mathrm{O}_{3}$ is direct with an acceptable deviation [56-59] at every points in its energy band structure. For understanding the inherent physical mechanism of the operating Schottky Ni/Au contacted and Ohmic $\mathrm{Ti} / \mathrm{Au}$ contacted $\beta-\mathrm{Ga}_{2} \mathrm{O}_{3}$ photodetectors, the systematic band diagrams of $\beta-\mathrm{Ga}_{2} \mathrm{O}_{3}$ with $\mathrm{Ti}$ and $\mathrm{Ni}$ in the dark and under the $254 \mathrm{~nm}$ UV light illumination are shown in figure 5(a)-(d). The work functions of $\mathrm{Ti}$ and $\mathrm{Ni}[\Phi(\mathrm{Ti})$ and $\Phi(\mathrm{Ni})]$ are $4.33 \mathrm{eV}$ and $5.15 \mathrm{eV}$, respectively, and the electron affinity of $\beta-\mathrm{Ga}_{2} \mathrm{O}_{3}\left[\chi\left(\beta-\mathrm{Ga}_{2} \mathrm{O}_{3}\right)\right]$ is about $4.00 \mathrm{eV}$ as reported [60-62]. So, the interface barriers of $\beta-\mathrm{Ga}_{2} \mathrm{O}_{3}$ with Ti and Ni $\left(\Delta \varphi_{T i-\beta-G a 2 O 3}\right.$ and $\left.\Delta \varphi_{N i-\beta-G a 2 O 3}\right)$ could be calculated to be $0.33 \mathrm{eV}$ and 1.15 $\mathrm{eV}$, on the basis of the Schottky-Mott rule [29, 30]. The puny interface barrier between Ti and $\beta$ $\mathrm{Ga}_{2} \mathrm{O}_{3}$ contributes to the Ohmic M-S contact, while the larger interface barrier between Ni and $\beta$ $\mathrm{Ga}_{2} \mathrm{O}_{3}$ leads to the Schottky M-S contact. The I-V behavior of Ohmic devices could be expressed by the electron tunneling, while for the Schottky contact, the I-V characteristic could be described by the thermionic emission (TE) theory [63-65]:

$$
\mathrm{J}=J_{0}\left(\exp \left(\frac{q V}{n k T}\right)-1\right)
$$

and

$$
J_{0}=A^{*} T^{2} \exp \left(-\varphi_{B} / k T\right)
$$

where $J_{0}$ is the saturation current density, A is the area of M-S contact, $A^{*}$ is the efficient Richardson constant $\left(A^{*}=\frac{4 \pi q m^{*} k^{2}}{h^{3}}=41.1 \mathrm{~A} / \mathrm{cm}^{2} \cdot K^{2}\right)$ by taking $\mathrm{m}^{*}$ of $0.342 m_{0}, m_{0}$ is the free electron mass of $\beta-\mathrm{Ga}_{2} \mathrm{O}_{3}[66,67], k$ is Boltzmann constant, and $\varphi_{B}$ is the barrier height and expressed as $\varphi_{B}=\frac{k T}{q} \ln \left(\frac{A^{*} T^{2}}{J_{0}}\right)$. As displayed in figure 5 , the built-in electrical field $\left(\mathrm{V}_{\text {built-in }}\right)$ is developed when the $\mathrm{Ni}$ and $\beta-\mathrm{Ga}_{2} \mathrm{O}_{3}$ contacts. In the dark, as shown in figure 5(a) and (c), the larger interface barrier in Schottky device could restrict electron transport across the $\mathrm{Ni} / \beta-\mathrm{Ga}_{2} \mathrm{O}_{3}$ interface, while the Ohmic device is almost like a radiation (UV light)-sensitive resistor with tiny interface barrier. Therefore, the $\mathrm{I}_{\text {dark }}$ in Ohmic device is larger than that in Schottky device as displayed in figure 2(a), and the Schottky device may be more sensitive to the small signal owing to its smaller $\mathrm{I}_{\text {dark. }}$ Under $254 \mathrm{~nm}$ UV light illuminations, as displayed in figure 5(b) and (d), the incident photons 
with energy ( $h v$ ) greater than the energy bandgap of the $\beta-\mathrm{Ga}_{2} \mathrm{O}_{3}$ thin film could be absorbed by the $\beta-\mathrm{Ga}_{2} \mathrm{O}_{3}$ material and then produce the photo-generated electron-hole pairs (electrons at valence band are motivated to the conduction band by absorbed photons, and correspondingly holes are produced at the valence band), thereby changing the electrical conductivity of $\beta-\mathrm{Ga}_{2} \mathrm{O}_{3}$. Given a voltage, the electrons in $\beta-\mathrm{Ga}_{2} \mathrm{O}_{3}$ are pushed to the conduction band, while the holes are driven to the valence band. For Ohmic Ti/Au contacted $\beta-\mathrm{Ga}_{2} \mathrm{O}_{3}$ photodetector studied here, the $\mathrm{I}_{\text {photo }}$ is linearly improved by the incident $254 \mathrm{~nm}$ UV light. While for the Schottky Ni/Au contacted $\beta$ $\mathrm{Ga}_{2} \mathrm{O}_{3}$ photodetector, the $\mathrm{I}-\mathrm{V}$ characteristics show Schottky (rectifying) behaviors owing to the interface barrier between Ni metal electrode and $\beta-\mathrm{Ga}_{2} \mathrm{O}_{3}$ thin film. This phenomenon could be obtained whether the $254 \mathrm{~nm}$ UV light is turned on or not [1].

(a)

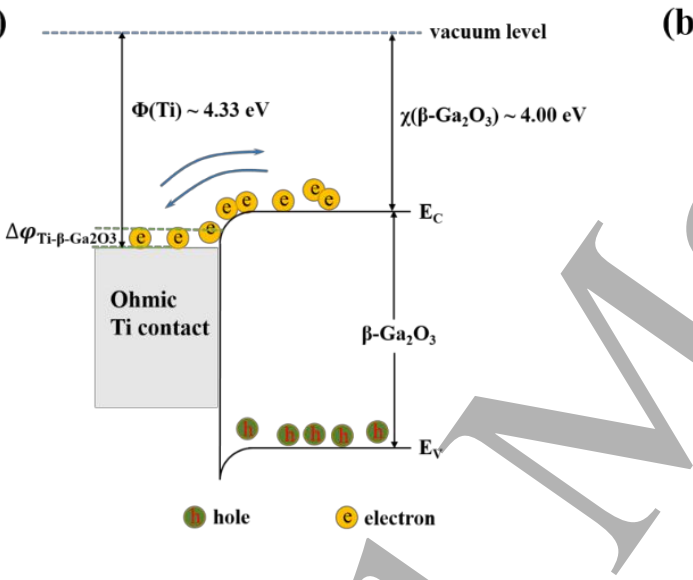

(c)



(b)

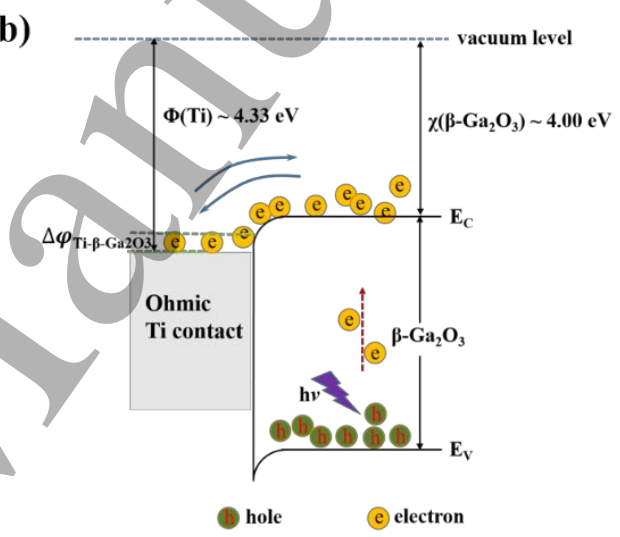

(d)

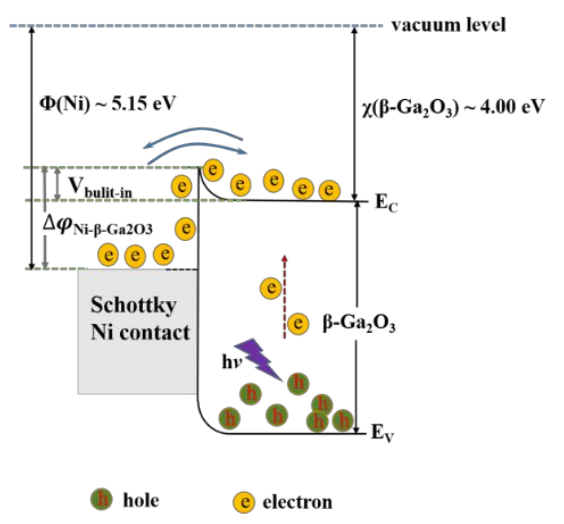

Figure 5. Band diagram of the $\beta-\mathrm{Ga}_{2} \mathrm{O}_{3}$ with $\mathrm{Ti}$ (a) in the dark and (b) under the $254 \mathrm{~nm}$ light illumination. Band diagram of the $\beta-\mathrm{Ga}_{2} \mathrm{O}_{3}$ with $\mathrm{Ni}(\mathrm{c})$ in the dark and (d) under the $254 \mathrm{~nm}$ light illumination.

For photodetectors, responsivity $(R)$ and detectivity $\left(D^{*}\right)$ are two vital parameters to evaluate the detector performances and could be described as following relationships [68]: 


$$
\mathrm{R}=\frac{I_{\text {photo }}-I_{\text {dark }}}{P_{\text {light }} \cdot S}
$$

and

$$
D^{*}=\frac{R_{254}}{\sqrt{2 q^{I} \text { dark } / S}}
$$

where $P_{\text {light }}$ is the UV light intensity used in the measurements, $S$ is the efficient radiant area in devices, $R_{254}$ is the photo responsivity under $254 \mathrm{~nm}$ light illumination. According to equation (4) and (5), the $R$ and $D^{*}$ by different driven voltages and light intensities are displayed in figure 6(a)(d) for Schottky and Ohmic $\beta-\mathrm{Ga}_{2} \mathrm{O}_{3}$ thin film based UV solar-blind photodetectors, Seen from figure 6(a), with the UV light intensity of $500 \mu \mathrm{W} / \mathrm{cm}^{2}$, the responsivities increase with the increasing voltages from $1 \mathrm{~V}$ to $5 \mathrm{~V}$, for both the Schottky (from $1.68 \mathrm{~mA} / \mathrm{W}$ to $0.14 \mathrm{~A} / \mathrm{W}$ ) and Ohmic (from $49 \mathrm{~mA} / \mathrm{W}$ to $0.25 \mathrm{~A} / \mathrm{W}$ ) devices. The responsivities for Ohmic devices ranging from $1 \mathrm{~V}$ to $5 \mathrm{~V}$ are all higher than those of Schottky devices, due to the larger $\mathrm{I}_{\text {photo }}$ of Ohmic devices compared to the Schottky devices, as well as the same $\mathrm{P}_{\text {light }}$ intensities and $S$, following the description in equation (4). In addition to the responsivities with different UV light intensities, the $R$ of Ohmic devices are also higher than those of Schottky devices, as shown in figure 6(c). The responsivities are increased by the increasing light intensity. By contrast, the Ohmic device could make more photogenerated electron-hole pairs to generate $\mathrm{I}_{\text {photo }}$ than the Schottky devices $[1,69-$ 72].

While the detectivies are governed by responsivities and the square root of $\mathrm{I}_{\text {dark }}$ for a photodetector, as given in equation (5). As shown in figure 6(b), the $D^{*}$ of Schottky devices are larger than that of Ohmic devices, owing to superlow $\mathrm{I}_{\text {dark }}\left(3.2 \times 10^{-16} \mathrm{~A}\right)$ of Schottky devices at 1 $\mathrm{V}$, which should be contributed to the rectifying effect caused by the $\mathrm{Ni} / \beta-\mathrm{Ga}_{2} \mathrm{O}_{3}$ interface barrier. In comparison, the $D^{*}$ of Schottky device at $2 \mathrm{~V}$ to $5 \mathrm{~V}$ are obviously smaller than that at $1 \mathrm{~V}$, this trend is in accordance with the rectifying I-V curves in figure 2(d). For Ohmic devices, the $\mathrm{I}_{d a r k}$ is always kept at $\sim 10^{-13}$, so the $D^{*}$ have the same evolutive tendency with $R$ as displayed in figure 6(a). In figure 6(d), the $D^{*}$ of Schottky devices are slightly larger than those of Ohmic devices at 5 V with $254 \mathrm{~nm} \mathrm{UV} \mathrm{light} \mathrm{intensity} \mathrm{from} 100 \mu \mathrm{W} / \mathrm{cm}^{2}$ to $500 \mu \mathrm{W} / \mathrm{cm}^{2}$ with a step of $100 \mu \mathrm{W} / \mathrm{cm}^{2}$, in accordance with the results in figure $6(\mathrm{~b})$ at $5 \mathrm{~V}$, indicating a better characterizing parameter for normalizing signal-to-noise ratio [1]. 

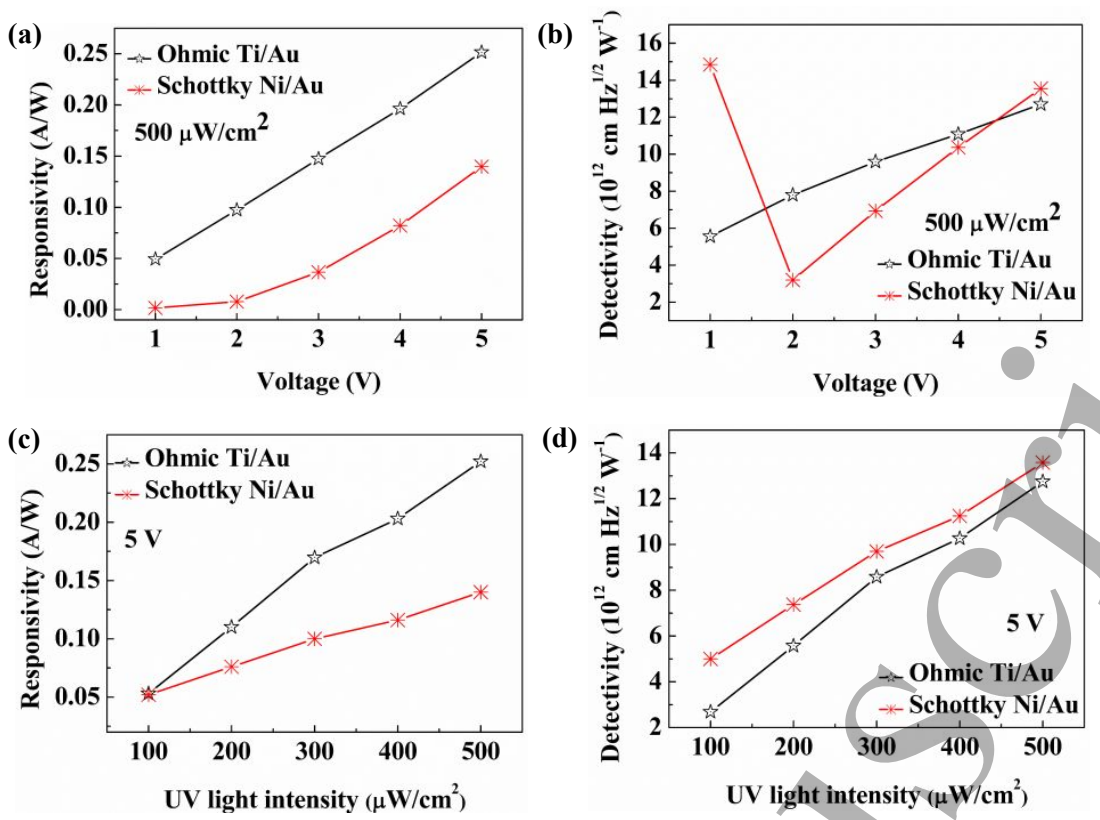

Figure 6. The voltage-dependent (a) responsivity and (b) detectivity for both Schottky Ni/Au and Ohmic Ti/Au contacted $\beta-\mathrm{Ga}_{2} \mathrm{O}_{3}$ thin film based UV solar-blind photodetectors with $254 \mathrm{~nm} \mathrm{UV}$ light intensity of $500 \mu \mathrm{W} / \mathrm{cm}^{2}$ from $1 \mathrm{~V}$ to $5 \mathrm{~V}$ with a step of $1 \mathrm{~V}$. The UV light intensity-dependent (c) responsivity and (d) detectivity for both Schottky Ni/Au and Ohmic Ti/Au contacted $\beta-\mathrm{Ga}_{2} \mathrm{O}_{3}$ thin film based UV solar-blind photodetectors at $5 \mathrm{~V}$ with $254 \mathrm{~nm}$ UV light intensities from 100 $\mu \mathrm{W} / \mathrm{cm}^{2}$ to $500 \mu \mathrm{W} / \mathrm{cm}^{2}$ with a step of $100 \mu \mathrm{W} / \mathrm{cm}^{2}$.

\section{Conclusions}

In summary, in this study, we grew $\beta-\mathrm{Ga}_{2} \mathrm{O}_{3}$ thin film by using metal-organic chemical vapor deposition technique, and made a comparison of optoelectrical properties of the prepared $\beta-\mathrm{Ga}_{2} \mathrm{O}_{3}$ thin films with Schottky Ni/Au and Ohmic Ti/Au contacted electrodes. The results show that Schottky device has higher photo-to-dark current ratios, and faster photo response speed than those of the Ohmic device. Working as a UV solar-blind photodetector, the responsivities of Schottky devices are larger than those of Ohmic devices. Owing the lower $\mathrm{I}_{d a r k}$, the $D^{*}$ of Schottky devices are superior to those of Ohmic devices at $5 \mathrm{~V}$ with light intensity from 100 to $500 \mu \mathrm{W} / \mathrm{cm}^{2}$. What's more, with $500 \mu \mathrm{W} / \mathrm{cm}^{2}$ light intensity, the different $D^{*}$ from $1 \mathrm{~V}$ to $5 \mathrm{~V}$ are also discussed on the basis of the Schottky I-V behaviors. In a word, we discussed and analyzed the differences between Schottky and Ohmic contacted $\beta-\mathrm{Ga}_{2} \mathrm{O}_{3}$ thin film based UV solar-blind photodetectors, and give out some inherent physical mechanism, in order to present the effect of metal- $\beta-\mathrm{Ga}_{2} \mathrm{O}_{3}$ contacted types (Schottky or Ohmic) on the devices performances, as well as their differences, operating as a UV solar-blind photodetector. 


\section{Acknowledgments}

This work was supported by the National Natural Science Foundation of China (Grant Nos. 61774019, 51572033, and 51572241), the Beijing Municipal Commission of Science and Technology, China (Grant No. SX2018-04). In addition, the authors acknowledged the Fundamental Research Funds for the Central Universities and the Foundation of State Key Laboratory of Information Photonics and Optical Communications (Beijing University of Posts and Telecommunications).

\section{References}

1. Razeghi M and Rogalski A 1996 J. Appl. Phys. 797433

2. Chen H, Liu K, Hu L, Al-Ghamdi A A and Fang X 2015 Mater. Today 18493

3. Sang L, Liao M and Sumiya M 2013 Sensors 1310482

4. Konstantatos G and Sargent E H 2010 Nat. Nanotechnol. 5391

5. Pearton S J, Yang J, Cary P H, Ren F, Kim J, Tadjer M J and Mastro M A 2018 Appl. Phys. Rev. 5011301

6. Liu Z, Li P G, Zhi Y S, Wang X L, Chu X L and Tang W H2019 Chin. Phys. B 28017105

7. Xu J, Zheng W and Huang F 2019 J. Mater. Chem. C 78753

8. Guo D Y, Wu Z P, An Y H, Guo X C, Chu X L, Sun C L, Li L H, Li P G and Tang W H 2014 Appl. Phys. Lett. 105023507

9. Kumar N, Arora K and Kumar M2019 J. Phys. D: Appl. Phys. 52335103

10. Qin Y, Sun H, Long S, Tompa G S, Salagaj T, Dong H, He Q, Jian G, Liu Q, Lv H and Liu M 2019 IEEE Electron Device Lett. 401475

11. Xu Y, Chen X, Zhou D, Ren F, Zhou J, Bai S, Lu H, Gu S, Zhang R, Zheng Y and Ye J 2019 IEEE Trans. Electron Devices 662276

12. Liu Z, Wang X, Liu Y, Guo D, Li S, Yan Z, Tan C -K, Li W, Li P and Tang W 2019 J. Mater. Chem. C 713920

13. Chen X, Mu W, Xu Y, Fu B, Jia Z, Ren F, Gu S, Zhang R, Zheng Y, Tao X and Ye J 2019 ACS Appl. Mater. Interfaces 117131

14. Dong L, Yu J, Jia R, Hu J, Zhang Y and Sun J 2019 Opt. Mater. Express 91191

15. Oshima T, Okuno T, Arai N, Suzuki N, Ohira S and Fujita S 2008 Appl. Phys. Express 1 011202

16. Chen M, Ma J, Li P, Xu H and Liu Y 2019 Opt. Express 278717

17. Zou R, Zhang Z, Liu Q, Hu J, Sang L, Liao M and Zhang W 2014 Small 101848

18. Wang S, Chen K, Zhao H, He C, Wu C, Guo D, Zhao N, Ungar G, Shen J, Chu X, Li P and Tang W H 2019 RSC Adv. 96064

19. Feng W, Wang X, Zhang J, Wang L, Zheng W, Hu P, Cao W and Yang B 2014 J. Mater. Chem. C 23254

20. Li Y, Tokizono T, Liao M, Zhong M, Koide Y, Yamada I and Delaunay J 2010 Adv. Funct. Mater. 203972 
21. An Y H, Guo D Y, Li S Y, Wu Z P, Huang Y Q, Li P G, Li L H and Tang W H 2016 J. Phys. D: Appl. Phys. 49285111

22. Liu Z, Wang X, Zhi Y S, Wang X L, Chu X L, Li S, Yan Z, Li P G and Tang W H 2019 Phys. Status Solidi A 1900570, [doi: 10.1002/pssa.201900570]

23. Guo D Y, Shi H Z, Qian Y P, Lv M, Li P G, Su Y L, Liu Q, Chen K, Wang S L, Cui C, Li C R and Tang W H 2017 Semicond. Sci. Technol. 32 03LT01

24. Guo D, Su Y, Shi H, Li P, Zhao N, Ye J, Wang S, Liu A, Chen Z, Li C and Tang W 2018 ACS Nano 1212827

25. Kong W Y, Wu G A, Wang K Y, Zhang T F, Zou Y F, Wang D D and Luo L B 2016 Adv. Mater. 2810725

26. Li S, Guo D, Li P, Wang X, Wang Y, Yan Z, Liu Z, Zhi Y, Huang Y, Wu Z and Tang W 2019 ACS Appl. Mater. Interfaces 1135105

27. Sze S M, Coleman D J and Loya A 1971 Solid-State Electron. 141209

28. Xue H W, He Q M, Jian G Z, Long S B, Pang T and Liu M 2018 Nanoscale Res. Lett. 13290

29. Mott N F 1939 Proc. R. Soc. (London) A 17127

30. Schottky W 1939 Z. Phys. 113367

31. Sze S M and Ng K K 2007 Physics of Semiconductor Devices (NJ: John Wiley \& Sons, Inc.)

32. Bae J, Kim H Y and Kim J 2017 ECS J. Solid State Sci. Technol. 6 Q3045

33. An Y H, Guo D Y, Li Z M, Wu Z P, Zhi Y S, Cui W, Zhao X L, Li P G and Tang W H 2016 RSC Adv. 666924

34. Chen X, Liu K, Zhang Z, Wang C, Li B, Zhao H, Zhao D and Shen D 2016 ACS Appl. Mater. Interfaces $\mathbf{8} 4185$

35. Cowley A M and Sze S M 1965 J. Appl. Phys. 363212

36. Mönch W 1970 Surf. Sci. 21443

37. Tung R T 1992 Phys. Rev. B 4513509

38. Jiao Y, Hellman A, Fang Y, Guo S and Kall M 2015 Sci. Rep. 511374

39. Li J G 1997 Mater. Chem. Phys. 47126

40. Thomson G W 1946 Chem. Rev. 381

41. Li Z, Jiao T, Hu D, Lv Y, Li W, Dong X, Zhang Y, Feng Z and Zhang B 2019 Coatings 9281

42. Mao S and Luo J 2019 J. Phys. D: Appl. Phys. 52503001

43. Michel J, Splith D, Rombach J, Papadogianni A, Berthold T, Krischok S, Grundmann M, Bierwagen O, von Wenckstern H and Himmerlich M 2019 ACS Appl. Mater. Interfaces 11 27073

44. Yang J, Sparks Z, Ren F, Pearton S J and Tadjer M 2018 J. Vac. Sci. Technol. B 36061201

45. Schultz T, Vogt S, Schlupp P, von Wenckstern H, Koch N and Grundmann M 2018 Phys. Rev. Applied 9064001

46. King P D C, Veal T D, Páyne D J, Bourlange A, Egdell R G and McConville C F 2008 Phys. Rev. Lett. 101116808

47. Hämäläinen J, Munnik F, Ritala M and Leskelä M 2008 Chem. Mater. 206840

48. Fleisch T H and Mains G J 1986 J. Phys. Chem. A 905317

49. Splith D, Müller S, von Wenckstern H and Grundmann M 2018 Proc. SPIE 10533 10533C

50. Hou C, Gazoni R M, Reeves R J and Allen M W 2019 IEEE Electron Device Lett. 40337

51. Jian G, He Q, Mu W, Fu B, Dong H, Qin Y, Zhang Y, Xue H, Long S, Jia Z, Lv H, Liu Q, Tao X and Liu M 2018 AIP Adv. 8015316 
52. Liu N, Fang G, Zeng W, Zhou H, Cheng F, Zheng Q, Yuan L, Zou X and Zhao X 2010 ACS Appl. Mater. Interfaces 21973

53. Mosbacker H L, Strzhemechny Y M, White B D, Smith P E, Look D C, Reynolds D C, Litton C W and Brillson L J 2005 Appl. Phys. Lett. 87012102

54. Allen M W and Durbin S M 2008 Appl. Phys. Lett. 92122110

55. Moloney J, Tesh O, Singh M, Roberts J W, Jarman J C, Lee L C, Huq T N, Brister J, Karboyan S, Kuball M, Chalker P R, Oliver R A and Massabua F C -P 2019 J. Phys. D: Appl. Phys. 52475101

56. Wang X L, Quhe R G, Zhi Y S, Liu Z, Huang Y Q, Dai X Q, Tang Y N, Wu Z P and Tang W H 2019 Superlattices Microstruct. 125330

57. Peelaers H and Van de Walle C G 2015 Phys. Status Solidi B 252828

58. Varley J B, Weber J R, Janotti A and Van de Walle C G 2010 Appl. Phys. Lett. 97142106

59. He H, Blanco M A and Pandey R 2006 Appl. Phys. Lett. 88261904

60. Michaelson H B 1977 J. Appl. Phys. 484729

61. Mohamed M, Irmscher K, Janowitz C, Galazka Z, Manzke R and Fornari R 2012 Appl. Phys. Lett. 101132106

62. Darowicki K, Krakowiak S and Slepski P 2006 Electrochim. Acta 512204

63. Furno M, Bonani F and Ghione G 2007 Solid-State Electron. 51466

64. Latreche A 2019 SN Appl. Sci. 1188

65. Harada T, Ito S and Tsukazaki 2019 Sci. Adv. 5 eaax5733

66. He H, Orlando R, Blanco M A, Pandey R, Amzallag E, Baraille I and Rerat M 2006 Phys. Rev. B 74195123

67. Sasaki K, Higashiwaki M, Kuramata A, Masui T and Yamakoshi S 2013 IEEE Electron Device Lett. 34493

68. Gong X, Tong M, Xia Y, Cai W, Moon J S, Cao Y, Yu G, Shieh C L, Nilsson B and Heeger A J 2009 Science 3251665

69. Rose A 1963 Concepts in Photoconductivity and Allied Problems (NY: Inter-science)

70. Rettie A J E, Chemelewski W D, Emin D and Mullins C B 2016 J. Phys. Chem. Lett. 7471

71. Kokum A F, Miranowicz A, Liberato S D, Savasta S and Nori F 2019 Nat. Rev. Phys. 119

72. Latreche A and Ouennoughi Z 2013 Semicond. Sci. Technol. 28105003 